\title{
Pencitraan Struktur Bawah Permukaan Dasar Perairan Kangean Menggunakan Data Seismik Refleksi 2D Multichannel
}

\author{
Tomi $^{a^{*}}$, Halasan Sihombing ${ }^{b}$ Muhardi ${ }^{\mathrm{a}}$
}

\author{
aProdi Geofisika FMIPA Universitas Tanjungpura Pontianak, bPoliteknik Negeri Pontianak \\ *Email : tomipotter96@gmail.com
}

\begin{abstract}
Abstrak
Perairan Kangean merupakan salah satu perairan yang termasuk dalam Cekungan Jawa Timur. Cekungan ini banyak diminati untuk eksplorasi hidrokarbon karena termasuk salah satu wilayah prospek minyak bumi dan gas di Indonesia. Penelitian ini bertujuan untuk mengidentifikasi struktur bawah permukaan dasar Perairan Kangean. Penelitian ini dilakukan dengan menginterpretasi pencitraan bawah permukaan menggunakan data seismik refleksi 2D multichannel hasil akuisisi Pusat Penelitian dan Pengembangan Geologi Kelautan (PPPGL). Hasil penelitian menunjukkan bahwa struktur bawah permukaan dasar Perairan Kangean teridentifikasi lipatan (fold) yang terdiri dari sinklin dan antiklin. Hasil penelitian juga menunjukkan bahwa pada penampang berarah Barat-Timur Perairan Kangean terdapat struktur berupa antiklin, sedangkan pada penampang berarah Utara-Selatan terdapat lipatan yang terdiri dari sinklin dan antiklin.
\end{abstract}

Kata Kunci : Antiklin, Pencitraan, Refleksi, Seismik, Sinklin

\section{Pendahuluan}

Indonesia merupakan negara berkembang yang kebutuhan energinya meningkat setiap tahun untuk mendukung pertumbuhan ekonomi dan juga penduduk. Hasil simulasi dengan model sistem dinamik menunjukkan bahwa pada tahun 2025 diperkirakan penyediaan bahan bakar minyak (BBM) dalam negeri hanya 651.092 juta barel, sedangkan konsumsi BBM membutuhkan 719.048 juta barel. Simulasi ini memperlihatkan kepada kita bahwa persediaan BBM diprediksi masih dapat mencukupi kebutuhan secara nasional hingga tahun 2016, sedangkan persediaan BBM tidak bisa lagi mencukupi kebutuhan secara nasional pada tahun 2017 sampai 2025 [1]. Maka dari itu, dalam rangka untuk mengantisipasi krisis energi di masa-masa mendatang perlu dilakukan upaya-upaya signifikan dalam pemenuhan kebutuhan energi nasional. Salah satu upaya tersebut adalah dengan melakukan eksplorasi minyak bumi dan gas (migas) maupun energi alternatif lainnya secara besar-besaran.

Perairan Kangean merupakan salah satu wilayah prospek migas di Indonesia. Perairan tersebut termasuk dalam Cekungan Jawa Timur. Cekungan ini banyak diminati untuk eskplorasi hidrokarbon[2].

Pencitraan bawah permukaan dasar perairan merupakan suatu keperluan dalam penelitian kebumian. Pencitraan ini dapat memodelkan bentuk struktur bawah permukaan tanpa melakukan pengamatan di bawah permukaan melainkan cukup dengan melakukan pengukuran di permukaan saja. Hasil citra bawah permukaan ini selanjutnya dapat digunakan untuk keperluan eksplorasi kekayaan bawah laut, mitigasi bencana alam maupun keperluan lainnya.

Metode seismik merupakan metode geofisika aktif yang dapat digunakan untuk mengidentifikasi keadaan bawah permukaan menggunakan prinsip perambatan gelombang seismik. Konsep dasar metode ini yaitu jika sumber gelombang seismik diaplikasikan di permukaan bumi, maka gelombang seismik akan menjalar ke bawah permukaan bumi ke segala arah. Hal ini dikarenakan material bawah permukaan bumi bersifat elastik. Gelombang seismik ini kemudian akan dipantulkan dan dibiaskan jika mengenai batas antar dua lapisan di bawah permukaan. Gelombang seismik yang dipantulkan dan dibiaskan tersebut akan dideteksi dengan geofon (khusus untuk di darat) atau hidrofon (khusus untuk di laut) yang dipasang di permukaan bumi. Detektor (geofon dan hidrofon) ini umumnya disusun sedemikian rupa sehingga posisi sumber ledakan dengan detektor membentuk garis lurus (profil line).

Data yang diperoleh merupakan sinyal gelombang seismik yang akan direkam oleh seismogram. Data ini berupa waktu tempuh gelombang dan jarak antar detektor terhadap sumber ledakan, yang berfungsi untuk memperkirakan besar kecepatan gelombang seismik di bawah permukaan. Data terseut diperlukan untuk melakukan interpretasi truktur lapisan bawah permukaan[3].

Penelitian ini bertujuan untuk untuk mengidentifikasi struktur bawah permukaan dasar Perairan Kangean. Struktur tersebut diidentifikasi berdasarkan hasil interpretasi 
pencitraan bawah permukaan menggunakan data seismik refleksi 2D multichannel.

\section{Metodologi}

Lokasi penelitian difokuskan pada bagian Barat Daya perairan Kangean, yang terletak di Utara Bali dan secara geografis terletak pada koordinat $114^{\circ} 51^{\prime}-115^{\circ} 16^{\prime}$ Bujur Timur dan $07^{\circ} 07^{\prime}--07^{\circ} 25^{\prime}$ Lintang Selatan. Luas daerah yang diteliti ini sekitar $1500 \mathrm{~km}^{2}$.

Penelitian ini menggunakan data mentah seismik refleksi 2D multichannel L.07, L.18, L.20, L.22, dan L.24 (Gambar 1) hasil akuisisi Pusat Penelitian dan Pengembangan Geologi Kelautan (PPPGL). Akuisisi tersebut dilakukan dengan jumlah channel 48 buah, interval penembakan $25 \mathrm{~m}$ dan interval penerima $12,5 \mathrm{~m}$.

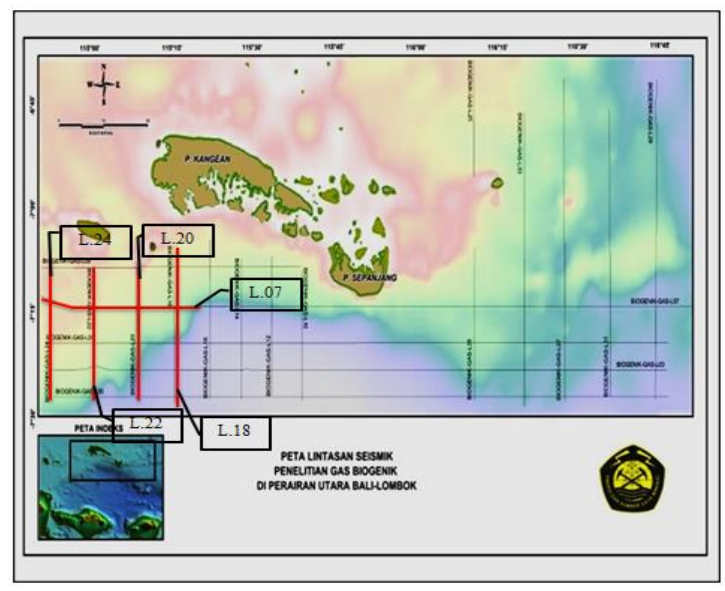

Gambar 1. Peta lokasi lintasan seismik. Garis merah merupakan lintasan yang dilakukan pengolahan data.

Penelitian ini dilakukan dengan dua tahapan utama. Adapun tahapan tersebut meliputi pengolahan data dan interpretasi struktur dari penampang seismik (Gambar 2). Tahapantahapan yang tertera pada Gambar 2 ini dilakukan pada setiap data lintasan seismik. Pengolahan data penulis lakukan di laboratorium PPPGL sedangkan proses interpretasi dilakukan di FMIPA Untan. Perangkat lunak yang digunakan adalah ProMAX 5000 dan Petrel. ProMAX 5000 digunakan untuk pengolahan data seismik sedangkan Petrel digunakan untuk menampilkan penampang seismik yang lebih mudah diinterpretasi.

Prosedur pengolahan data dilakukan mulai dari input data hingga Segy Output. Filtering (penapisan) dilakukan dengan bandpass filter, analisis kecepatan dilakukan dengan metode semblance dan migrasi dilakukan dengan Kirchoff Time Migration. Adapun jarak antar Common Depth Point (CDP) adalah sebesar 6,25 $\mathrm{m}$.
Gelombang seismik merambat dengan kecepatan tertentu pada medium bumi yang dilaluinya. Hasil perkalian antara densitas medium $\rho\left(\mathrm{kg} / \mathrm{m}^{3}\right)$ dan kecepatan gelombang $\mathrm{v}$ $(\mathrm{m} / \mathrm{s})$ yang melewatinya dinamakan impedansi akustik Z $\left(\mathrm{kg} / \mathrm{m}^{2} \mathrm{~s}\right)$, atau dirumuskan sebagai[4]:

$$
\mathrm{Z}=\rho \mathrm{v}
$$

Koefisien refleksi merupakan nilai yang menunjukkan bidang batas antar dua lapisan yang masing-masing mempunyai impedansi akustik. Koefisien refleksi gelombang seismik yang mengenai bidang batas antar dua lapisan dirumuskan sebagai:

$$
\mathrm{R}=\frac{\mathrm{Z}_{1}-\mathrm{Z}_{0}}{\mathrm{Z}_{1}+\mathrm{Z}_{0}}
$$

$\mathrm{Z}_{0}$ dan $\mathrm{Z}_{1}$ merupakan impedansi akustik lapisan pertama dan kedua[5].

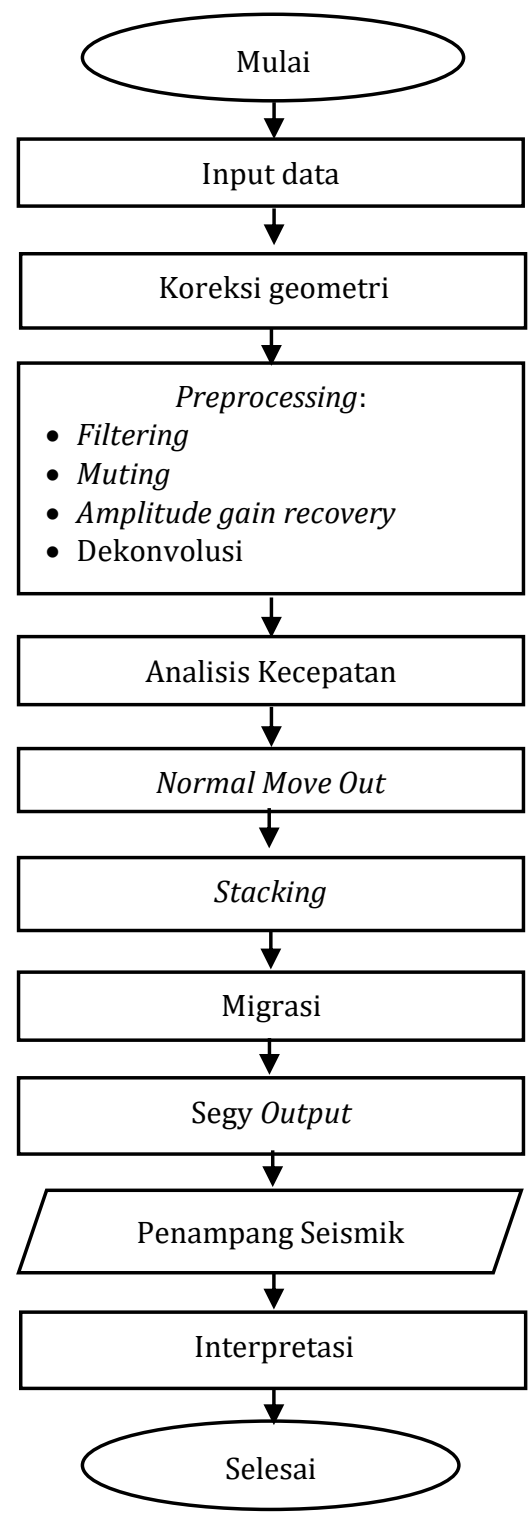

Gambar 2. Diagram alir penelitian 


\section{Hasil dan Pembahasan}

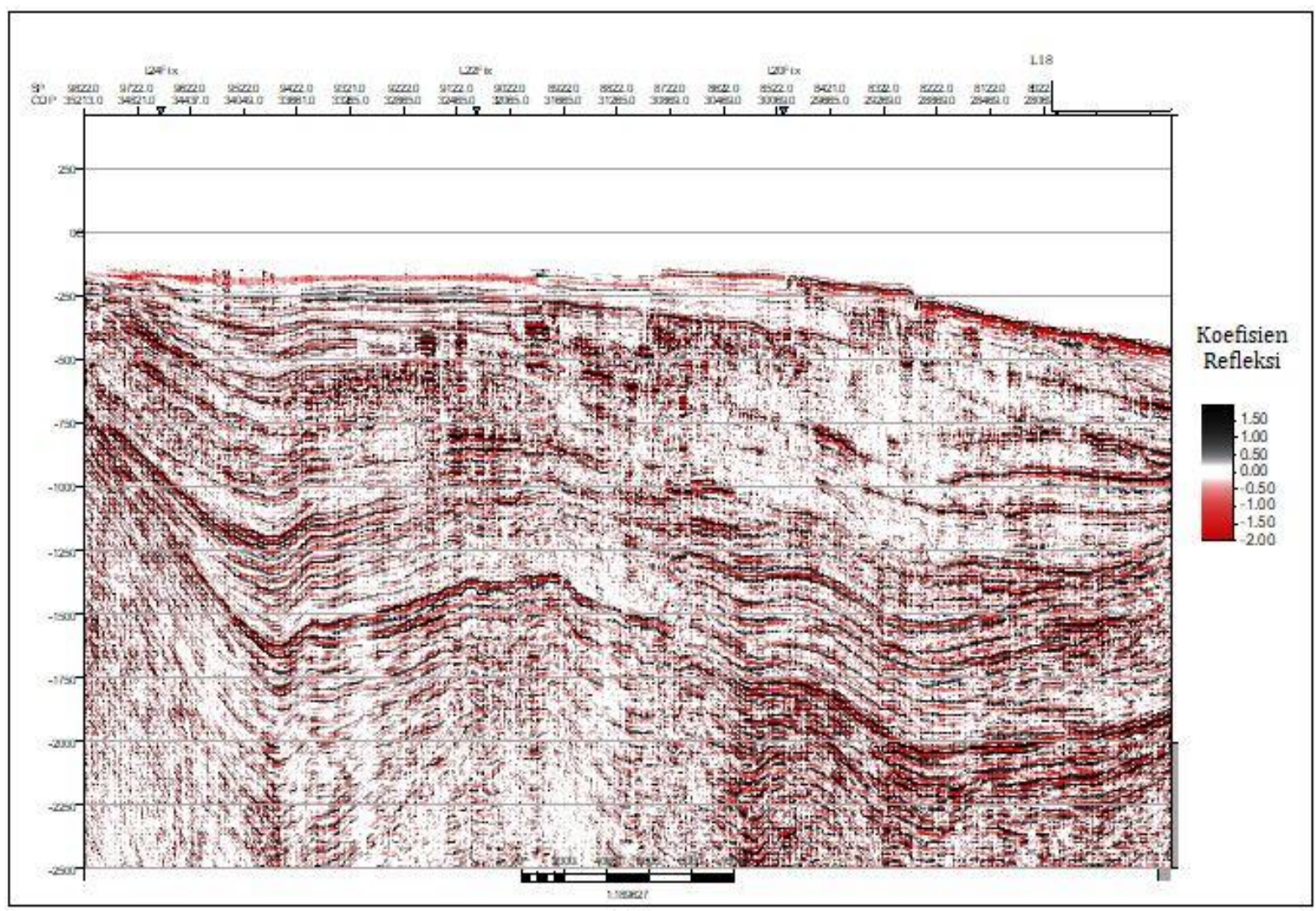

Gambar 3. Penampang seismik 2D pada Lintasan L.07

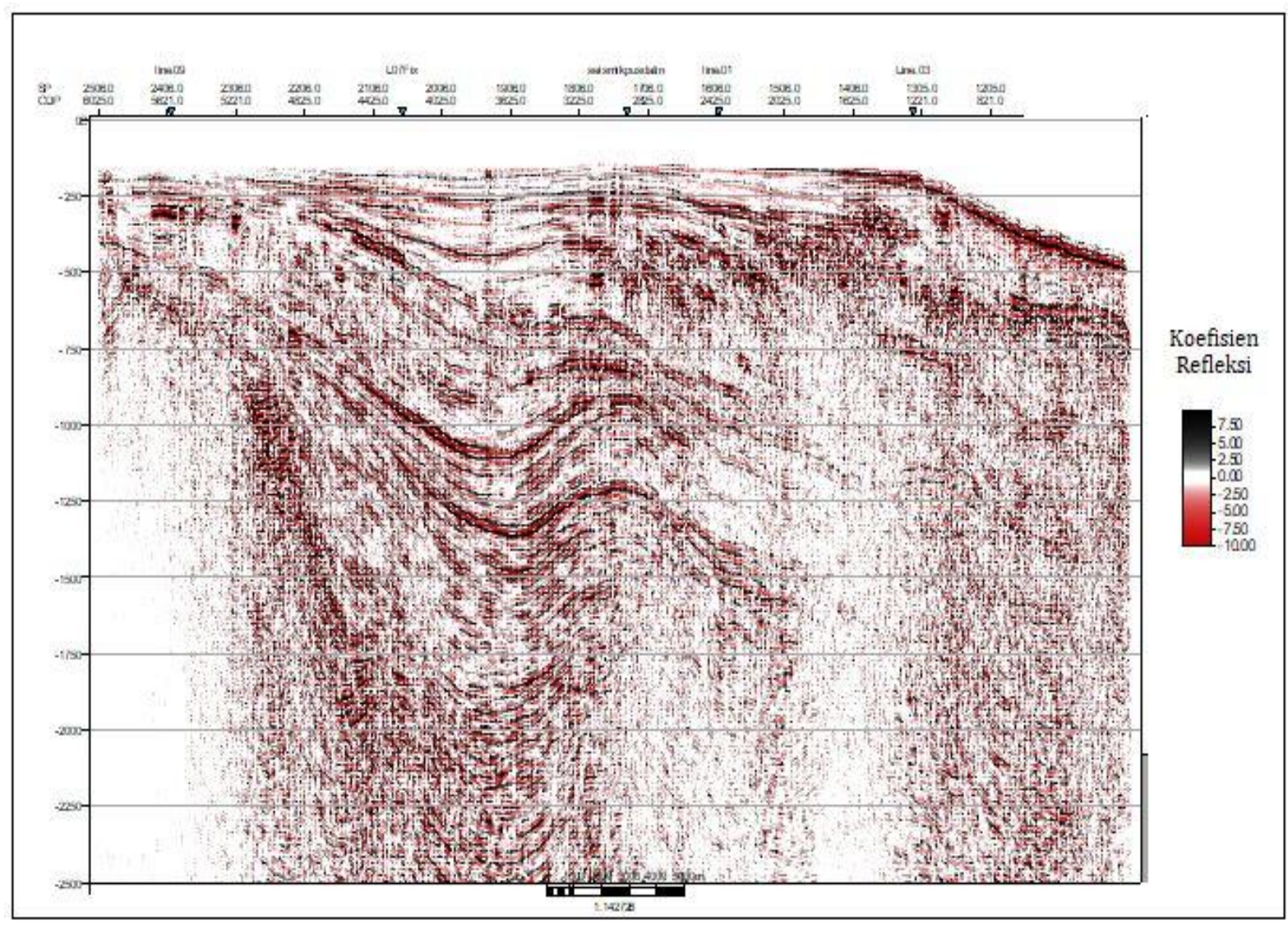

Gambar 4. Penampang seismik 2D pada Lintasan L.24 


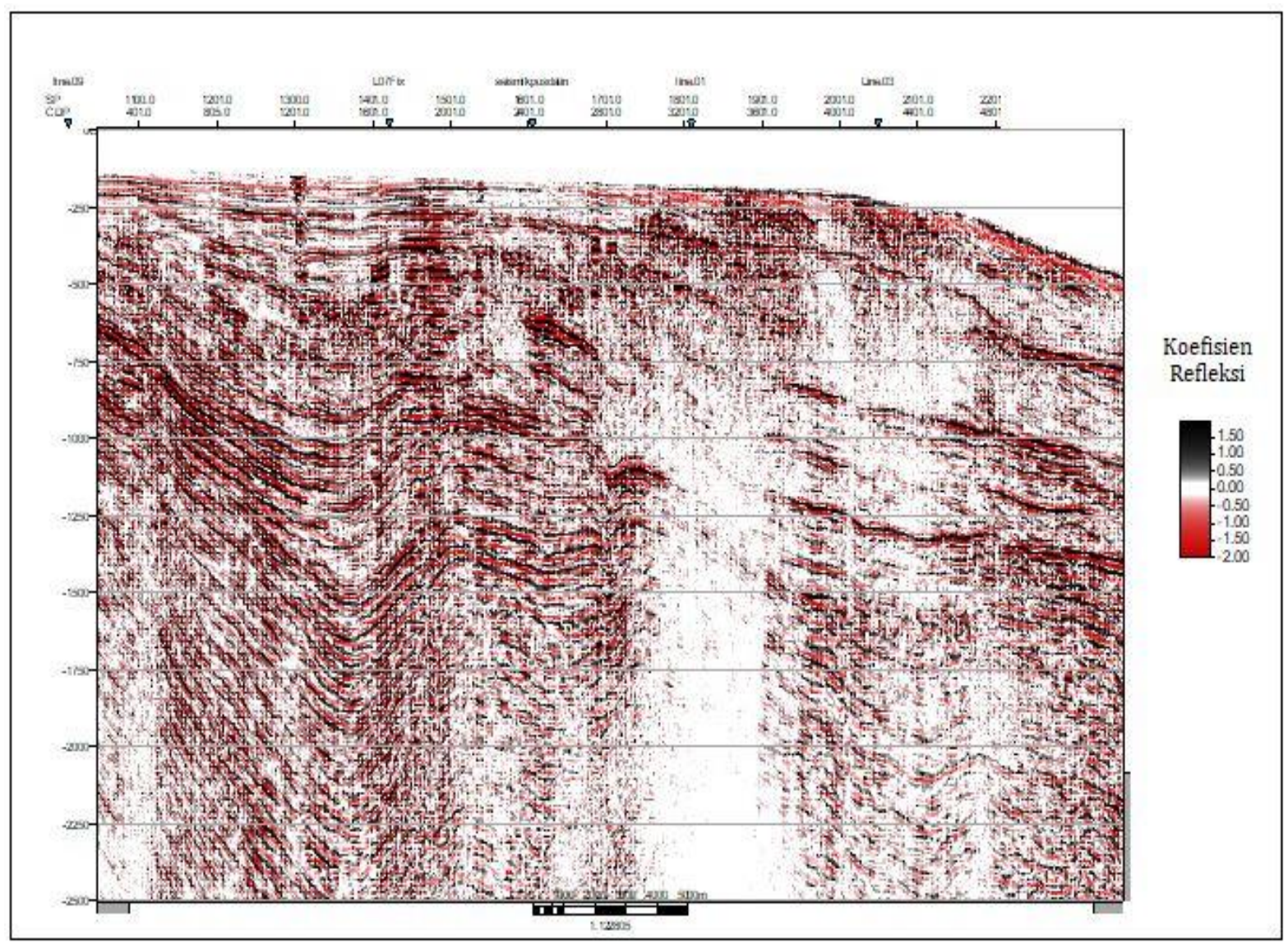

Gambar 5. Penampang seismik 2D pada Lintasan L.22

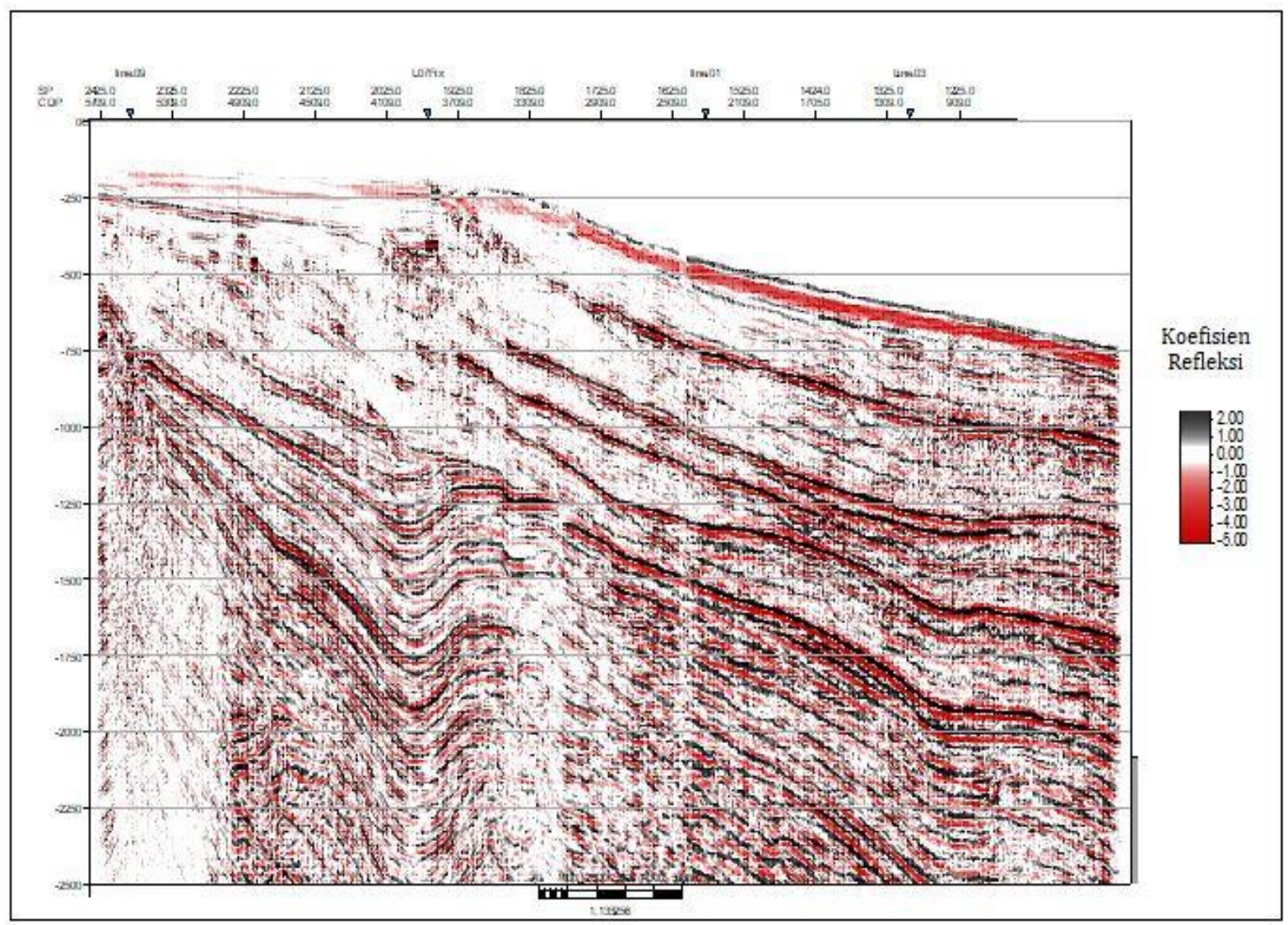

Gambar 6. Penampang seismik 2D pada Lintasan L.20 


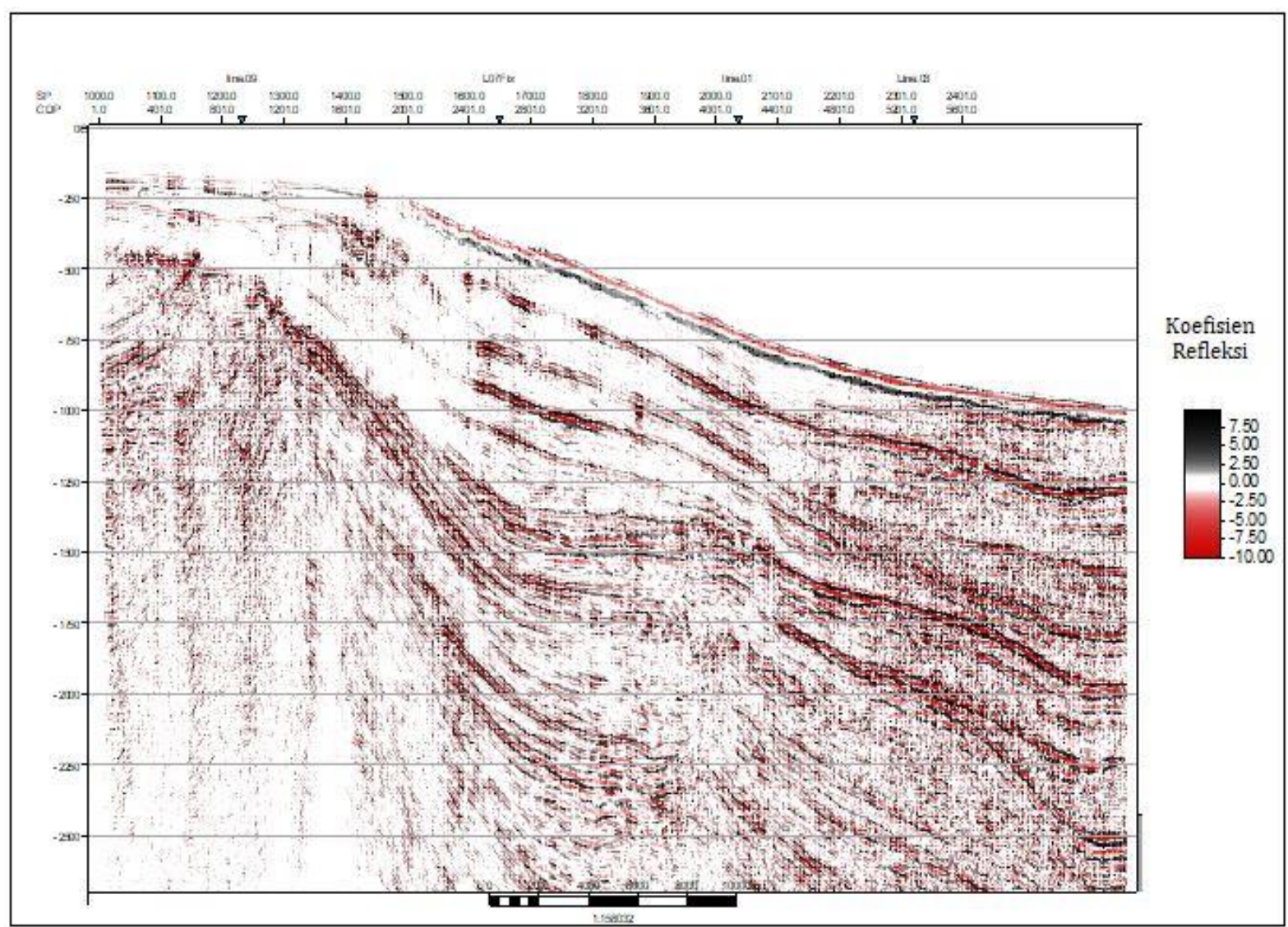

Gambar 7. Penampang seismik 2D pada Lintasan L.18

Gambar 3 merupakan gambar penampang seismik L.07 Perairan Kangean yang membentang dari Barat ke Timur. Lintasan ini berpotongan dengan lintasan L.24, L.22, L.20 dan L.18 berturut turut di sekitar CDP 34600, 32300, 30000 dan di sekitar CDP 28000. Lintasan yang saling berpotongan tersebut dimaksudkan agar penampang-penampang seismik saling terkait sehingga data yang dihasilkan dapat memberikan gambaran bawah permukaan yang lebih valid. Pada penampang L.07 dapat diketahui terdapat struktur berupa antiklin di interval CDP 34000-29000 pada two way time (twt) -1000 ms hingga -2000 ms.

Gambar 4 merupakan gambar penampang seismik L.24 Perairan Kangean yang membentang dari Utara ke Selatan. Lintasan L.24 ini berpotongan dengan L.07 di sekitar CDP 4225. Pada penampang L.24 diketahui terdapat struktur berupa lipatan (fold) yang terdiri dari sinklin dan antiklin yang terlihat di sekitar CDP 4425-2425 pada twt -750 ms hingga $-1500 \mathrm{~ms}$.

Gambar 5 merupakan gambar penampang seismik L.22 Perairan Kangean yang membentang dari Utara ke Selatan. Lintasan L.22 ini berpotongan dengan L.07 di sekitar CDP 1700. Pada penampang L.22 diketahui terdapat struktur berupa lipatan yang terdiri dari sinklin dan antiklin yang terlihat di sekitar CDP 8053600 pada twt $-750 \mathrm{~ms}$ hingga $-1500 \mathrm{~ms}$.

Gambar 6 merupakan gambar penampang seismik L.20 Perairan Kangean yang membentang dari Utara ke Selatan. Lintasan L.20 ini berpotongan dengan L.07 di sekitar CDP 3900. Pada penampang L.20 diketahui terdapat struktur berupa lipatan yang terdiri dari sinklin dan antiklin yang terlihat di sekitar CDP 49002500 pada twt $-1000 \mathrm{~ms}$ hingga $-2000 \mathrm{~ms}$. Struktur lipatan pada penampang berarah Utara-Selatan di Perairan Kangean ini diketahui diakibatkan oleh gaya kompresi dari UtaraSelatan[6].

Gambar 7 merupakan gambar penampang seismik L.18 Perairan Kangean yang membentang dari Utara ke Selatan. Lintasan L.18 ini berpotongan dengan L.07 di sekitar CDP 2600. Pada penampang L.18 tidak ditemukan struktur berupa pelipatan baik sinklin maupun antiklin.

\section{Kesimpulan}

Hasil penelitian menunjukkan bahwa struktur bawah permukaan dasar Perairan Kangean teridentifikasi lipatan yang terdiri dari sinklin dan antiklin. Hasil penelitian juga menunjukkan bahwa pada penampang berarah Barat-Timur Perairan Kangean terdapat 
struktur berupa antiklin, sedangkan pada penampang berarah Utara-Selatan terdapat lipatan yang terdiri dari sinklin dan antiklin.

\section{Ucapan Terima Kasih}

Penulis mengucapkan terima kasih kepada Comdev \& Outreaching Universitas Tanjungpura atas bantuan dana riset. Penulis juga mengucapkan terima kasih kepada Bapak Shaska Ramadhan Zulivandama, S.T selaku pembimbing teknis selama penelitian di PPPGL.

\section{Daftar Pustaka}

[1] Sa'adah, A. F., Fauzi, A. and Juanda, B., Peramalan Penyediaan dan Konsumsi Bahan Bakar Minyak Indonesia dengan Model Sistem Dinamik, Jurnal Ekonomi dan Pembangunan Indonesia, 17(2), 118-137, 2018.

[2] Satyana, A. H. and Purwaningsih, M. E. M., Geochemistry and Habitat Of Oil and Gas in The East Java Basin: Regional Evaluation and New Observations, Indonesian Association of Geologists, Http: www.researchgate.net, (accessed 4 May 2019).

[3] Permana, U., Triyoso, K. and Sanjaya, M., Pengolahan Data Seismlk Refleksi 2D Untuk Memetakan Struktur Bawah Permukaan Lapangan X Prabumulih Sumatra Selatan, Journal of Physics, 2(1), 28-37, 2015.

[4] Zuhrial, R. I., Bernhard, T. and Ramalis, T. R., Pencitraan Bawah Permukaan Dasar Laut Perairan Seram dengan Penampang Seismik 2D dan Batimetri, Fibusi (JoF), 3(1), i-ix, 2015.

[5] Haq, M., Analisa Atribut Amplitudo Seismik Untuk Karakterisasi Reservoar Pada Cekungan Sumatera Selatan, Skripsi, Fakultas Matematika dan Ilmu Pengetahuan Alam, Universitas Indonesia, Jakarta, 2009.

[6] Setiady, D., Astawa, I N., Hermansyah, G. M., Lugra, I W. and Nainggolan, T. B., Stratigrafi Perairan Utara Bali dari Hasil Interpretasi Seismik 2D, Jurnal Geologi Kelautan, 15(2), 95-106, 2017. 